East African Journal of Science, Technology and Innovation, Vol. 2 (3): June 2021

This article is licensed under a Creative Commons license, Attribution 4.0 International (CC BY NC SA 4.0)

\title{
Epidemiological patterns of Rift Valley Fever from diverse habitats during an extreme unprecedented flooding of Lake Baringo basin, Kenya, 2012-2013
}

\author{
1GICHERU M., 2MWANGI M B., 3ONYANGO A I., 4MICHUKI G N., ${ }^{3 *}$ KAMAU S K
}

1School of Pure and Applied Sciences, Kenyatta University, P.O. Box 43844-00100 Nairobi Kenya.

2Department of Physical \& Biological Sciences, Murang'a University of Technology P.O. Box 75-10200, Murang'a, Kenya

${ }^{3}$ Kabete Veterinary Investigation Laboratories, Directorate of Veterinary Services, P.O. Box Private Bag-00625 Kangemi, Nairobi

${ }^{4}$ The African Genomics Centre and Consultancy, P.O. Box 381-00517 Nairobi, Kenya

*Corresponding author: kamaukabochi@gmail.com

\begin{abstract}
Mosquitoes' ecology and associated arboviruses are heavily influenced by precipitation and retention of water in the environment. In 2011 and 2014, unprecedented floods occurred in Lake Baringo basin inundating approximate $88 \mathrm{~km} 2$ of the shoreline land. This caused abrupt environmental changes raising fears of an outbreak of Rift Valley Fever (RVF) disease. This study was carried out to determine the situation of RVF disease in livestock from diverse habitats during the extreme unprecedented flooding phenomenon that occurred in Lake Baringo basin, in 2012-2013. Blood was drawn from ear vein of livestock selected randomly from the three study areas (lakeshore land, swamp marshy and dry rangeland habitats). Mosquitoes were trapped using CDC light traps and identified morphologically. From a total of 77 blood samples, eight were positive for RVF virus (RVFV) representing an overall infection of $12 \%$. RVF prevalence from livestock resident in flooded lakeshore land habitat was $2.6 \%(\mathrm{~N}=77)$ compared to the swamp marshy habitat at $7.8 \%(\mathrm{~N}=77)$. No infections were recorded from dry rangeland $(0 \%)$. Mosquitoes of genus Mansonia dominated the catches in flooded lakeshore (98\%). Highest individual catches of mosquitoes of genus Aedes was from swamp marshy area whose abundance was $96.8 \%$ and below $2 \%$ in other habitats. The Simpson's Diversity Index for mosquitoes from swamp marshy habitat was 0.56, dry rangeland 0.57 and lakeshore land 0.13 . The flooded lakeshore land was the most affected by the unprecedented floods resulting in uneven mosquito diversity and subsequently low prevalence of RVF in this habitat. This could be attributed to prolonged disruption of biotic and abiotic factors creating unfavourable breeding sites of multiple species of primary vectors of RVF in flooded lakeshore land unlike in other habitats.
\end{abstract}

Keywords: Lake Baringo; unprecedented floods; RVF prevalence; livestock; habitat

Cite as: Kamau et al., (2021). Epidemiological patterns of Rift Valley Fever from diverse habitats during an extreme unprecedented flooding of Lake Baringo basin, Kenya,

2012-2013. East African Journal of Science, Technology and Innovation 2(3).

Received: $\quad 23 / 02 / 21$

Accepted: $\quad 25 / 05 / 21$

Published: $\quad 25 / 06 / 21$

\section{Introduction}

Stratification of an ecosystem into several diverse habitats is important in understanding environmental connection with the hosts, pathogens and vectors (Restrepo et al., 2016). These variations help in giving an insight into spatial epidemiological patterns of a disease that could be a precursor to an outbreak (Wangara et al., 2019). Lake Baringo basin harbours diversity of habitats whose composition of fauna and flora is influenced by human activities and environmental changes (Odada et al., 2006). The basin has 
severally experienced outbreaks of Rift Valley Fever (RVF) which is a zoonotic disease attributed to mosquitoes and floods caused by El nino rains (Nanyingi et al., 2015; Tigoi et al., 2015).

The RVF virus belongs to order Bunyavirales, Family Phenuiviridae and genus Phlebovirus (Abudurexiti et al., 2019). The disease was first described in Kenya in 1931 (Daubney et al., 1931). The Rift Valley Fever virus (RVFV) is able to invade diverse ecological systems (Jost et al., 2010). During heavy rains and particularly El nino that cause floods, there are increased number of breeding sites for the mosquitoes and hence intensifying virus transmission and circulation (Anyamba et al., 2001). The disease primarily affects cattle, sheep, and goats, but also people (Jost et al., 2010). Export and import of infected livestock is believed to be responsible for transmission across the borders of different countries (Chevalier et al., 2004). One of the most effective methods of detecting arboviruses is by use of Polymerase Chain Reaction (PCR) (Johnson et al., 2012).

The RVF disease epidemics usually occur after every 10 years with the virus able to invade diverse ecological systems (Jost et al., 2010). In South Africa, the disease was reported first in 1950, Namibia in 1955 and Egypt in 1977-1978. In 2000, an outbreak in Saudi Arabia caused death of 224 people (Chevalier et al., 2004). Kenya have experienced 11 national outbreaks of RVF with an average inter-epizootic period of three to four years between 1951 and 2007 (Nanyingi et al., 2015). The outbreaks were mostly attributed to Elnino/Southern Oscillation phenomenon (ENSO) rains causing flooding (Nanyingi et al., 2015) with the notable incidents having occurred in 19971998 (Okech et al., 2019) and 2006-2007 (Sang et al., 2010). In 2006/2007, an outbreak was reported in Garissa, Ijara, Maragwa, Thika, Baringo and Kilifi (Breiman et al., 2008; Munyua et al., 2010). The outbreak had the highest livestock morbidity and mortality rates including 90 human deaths (Breiman et al., 2010; Nguku et al., 2010). On a macroeconomic scale, losses from an outbreak of RVF in 2006-2007 is estimated to have been in range of Ksh 2.1 billion (US\$32 million) on the Kenyan economy, based on its negative impacts on agriculture and other sectors like transport and services among others (Rich \& Wanyoike, 2010).

Flooding, either from rainfall, artificially induced or unprecedented in any form results in creation of several ecotope layers in a habitat that affect mosquitos' distribution, breeding and eventual diseases transmission (Paula et al., 2012). For a period of over 30 years, Lake Baringo was experiencing a decreasing trend of the waters, from a depth of $8 \mathrm{~m}$ in 1976 to $1.7 \mathrm{~m}$ in 2001 (Okech et al., 2019). The area covered by water along the shores of the lake followed a similar trend with submerged land shrinking from $219 \mathrm{~km}^{2}$ in $1976,136 \mathrm{~km}^{2}$ in 1986, to $114 \mathrm{~km}^{2}$ in 2001 (Okech et al., 2019). In 2010 to 2014, unprecedented and extreme floods occurred in Lake Baringo as a result of the rise in lake waters that displaced people from their homes and submerged acres of land along the shores. Gradual overflow of waters into the land around the lake covered expansive areas, soaking the vegetation, animal and domestic wastes. This was a rare form of flooding phenomenon said to recur after every 50 years and caused by geological disturbances and earths' tectonic movements (Obando et al., 2016; Okech et al., 2019). According to Onywere (2013b), between January 2010 September 2013, the floods resulted in water rising from a low of $143.6 \mathrm{~km}^{2}$ in January 2010 to a high of $231.6 \mathrm{~km}^{2}$ in September 2013. The rising waters inundated $88 \mathrm{~km}^{2}(61.3 \%)$ of lakeshore land surpassing any previous flooded water marks on the land (Obando et al., 2016).

This study aimed at assessing spatial risks, vectors and RVF prevalence in livestock resident in diverse habitats of Lake Baringo basin during the period of prolonged, extreme and unprecedented flooding in 2012-2013. The study identifies some of the critical environmental factors and exposure, the interaction with vectors, hosts and pathogens in sustenance of RVFV. The findings would be helpful in advising on vector policy, reviewing 
of RVF disease risk maps and contingency plans.

\section{Materials and methods}

\section{Study area}

Lake Baringo basin is located in Baringo County, at an altitude of $950 \mathrm{~m}$ above sea level, latitudes $00^{\circ} 28^{\prime} \mathrm{N}$ and $00^{\circ} 32^{\prime} \mathrm{N}$ and longitudes $36^{0} 58^{\prime} 60 \mathrm{E}$ and $36^{\circ} 00^{\prime} \mathrm{E}$. The lake and the basin is located in semi-arid area, ecological zone VI (Johansson and Svensson, 2002). It experiences bimodal rainfall with the long rain season starting from March-June and a short rain season from October - November, averaging $1200 \mathrm{~mm}$ per year with a range of $300-700 \mathrm{~mm}$ (Wetang'ula et al., 2012).

\section{Selection of study sites}

Lake Baringo basin is regarded as an RVF endemic area (Tigoi et al., 2015). In the basin, three study sites were selected to represent three strata of habitats; flooded lakeshore land (represented by Ngambo village), swamp marshy (represented by Kapkuikui village) and dry rangeland habitat (represented by Kimelel) (Figure 1). The flooded lakeshore land included several villages with Ngambo selected to represent the rest because of its accessibility. Ngambo Village lies at latitude $0^{\circ} 30^{\prime} 30.6^{\prime \prime} \mathrm{N}$, longitude $36^{\circ} 03^{\prime} 36.7^{\prime \prime} \mathrm{E}$ and an altitude of 995 metres above sea level. The area was used for subsistence crop and livestock farming. Prosopis juliflora was the dominant plant covering large tracks of land. Floating macrophytes covered most of water surface following flooding in the lakeshore ecological habitat. This type of vegetation is said to offer conducive habitat for mosquitoes breeding (Mwangi \& Swallow, 2005).

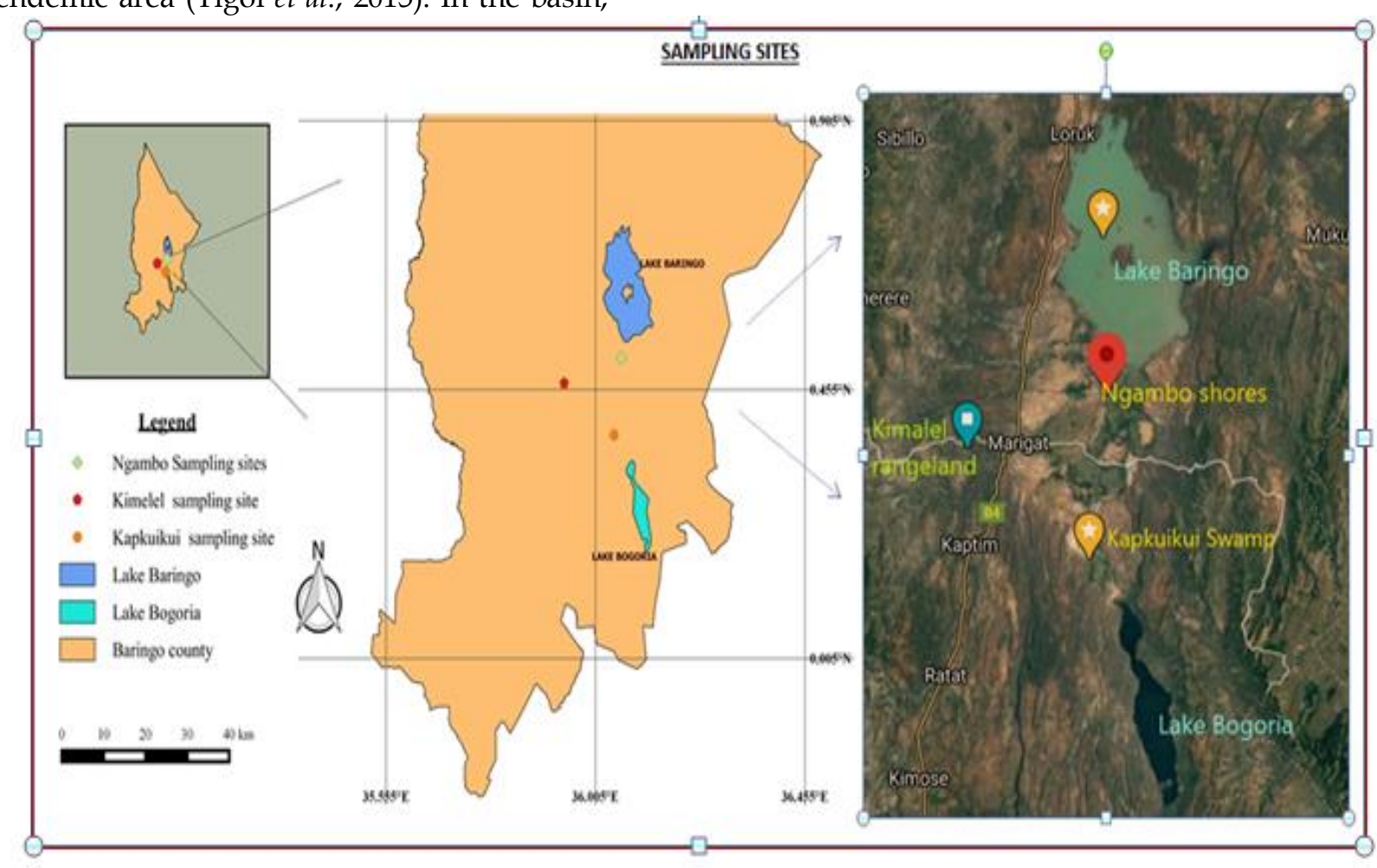

Figure 1. Location of study sites from Lake Baringo basin (flooding lakeshore land at Ngambo; swamp marshy at Kapkuikui and dry rangeland ecological habitats at Kimelel

The swamp marshy habitat located at Kapkuikui lies between Lake Baringo and Lake Bogoria at latitude $0^{\circ} 22^{\prime} 44.6^{\prime \prime} \mathrm{N}$, longitude $36^{\circ} 02^{\prime} 42.1^{\prime \prime} \mathrm{E}$ and altitude of 1004 metres above sea level. It forms an extensive soggy ground of Loboi wetlands that are fed by underground and surface springs including River Loboi. The main features of the swamp are extensive 
growth of emergent macrophytes dominated by Cyperus papyrus and Typha domingenis (Terer et al., 2012). It is a fragile ecosystem which is easily destabilized by both natural and anthropogenic activities (Odada et al., 2006). The area is extensively used as a communal grazing area with wildlife such as Zebras, Ostriches, and different species of antelopes flocking along with grazing livestock.

The dry rangeland habitat is located in Kimelel at latitude $0^{\circ} 27^{\prime} 57.2^{\prime \prime} \mathrm{N}$, longitude $35^{\circ} 56^{\prime} 15.7^{\prime \prime} \mathrm{E}$ and altitude 1172 meters above sea level. There is a seasonal dam that fills with water during the rainy season but dries up during the dry season. The habitat is characterized by scattered acacia species, grass and sparse shrubs. Unlike the other habitats around Lake Baringo, only a few $P$. juliflora grow in the area. This habitat is separated from the other two by a sharp escarpment.

\section{Sample collection}

This was a longitudinal research carried out from October 2012 - October 2013. From the three study habitats, stratified random sampling of the homesteads was carried out where those rearing the four species of livestock; indigenous cattle, sheep, goats and poultry were profiled. To ensure there was no inter-effects of one homestead to the other, the selected homesteads stood at an approximate distance of one kilometre from each other. Each study habitat had two homes selected where livestock were sampled at the end of every two months. Whole blood was drawn from the ear vein but in case of indigenous poultry, blood was obtained from wing vein. Bar-coded vacutainer tubes coated with EDTA were used in both cases. The sample blood was aliquoted into $2 \mathrm{~mL}$ cryovials, carried to laboratory in a container packed with iced $\mathrm{CO}_{2}$ ready for storage and preservation in biorepository nitrogen liquid tanks awaiting further analysis. Monthly trapping of mosquitoes was carried out from the three habitats using CDC traps for 12 months. The catches from each habitat were identified using morphological features and recorded.

\section{Sample size}

The selection of livestock to be sampled in the research was purposive. Those aged above three years and had no clinical history of a disease over the last four months were recruited into the study. At the beginning of each sampling session, physical examination for any form of illness was done to the target animals by a veterinarian. Only those perceived to be ill and of poor body condition had their samples taken and eventually screened for RVFV. A total of 77 samples were screened using PCR of which 22 were cattle, 16 sheep, 17 goats and 22 poultry.

\section{Identification of arboviruses}

The procedure for Nested PCR was used to synthesise cDNA. The RNA was extracted from the livestock blood samples using QIAamp viral RNA extraction protocol (QIAQEN, Thermo Fisher, California, USA) to make total RNA. A volume of $200 \mu \mathrm{L}$ sample blood was added to $60 \mu \mathrm{L}$ of red blood cell lysis buffer, incubated for five (5) minutes at room temperature and then centrifuged for one (1) minute. The products were pre-filtered, isolated, purified and concentrated into a total RNA end product. The extracted RNA was then eluted with $\geq 6 \mu \mathrm{L}$ of RNase-free water. The First cDNA was synthesised from extracted total RNA using Superscript Kit II (Invitrogen, Thermo Fisher, California, USA) protocol and then stored in a freezer at $-20^{\circ} \mathrm{C}$. The Second Strand cDNA was synthesized as described in the QIAGEN quick PCR Purification Kit (QIAGEN, Thermo Fisher, Hilden, Germany) in readiness for amplification. Sequences of the primer used in the study (5'-ATG-CTG-GGA-AGT-GATGAG-CG-3') and (5'-GAT-TTG-CAG-AGTGGT-CGT-C-3') were as defined in Terrestrial Manual for OIE (OIE Terrestrial Manual, 2016).

\section{Statistical analysis}

The data collected was analysed using SPSS software Ver.16 and Microsoft Office Excel Data Analysis Ver. 2013. Simpson's Diversity Index was calculated using an online diversity calculator (Young, 2021). The percentage of 
livestock species infected with RVF disease was expressed as a period prevalence. The significance differences in infection for livestock species resident in the three ecological habitats was calculated using ANOVA at $p<0.05$. For paired comparison between two habitats, t-test was set at $\mathrm{P}<0.05$. Odds ratio (OR) was used to compute the measure of association for the disease and exposure to dominant vector in flooded shoreline.

\section{Results}

Mosquito infestation in the three habitats from Lake Baringo basin

A total of 386,625 individual mosquitoes were trapped in the three study habitats. The flooded lakeshore land habitat had the highest catch of mosquitoes constituting $88.9 \%$, swamp marshy $10.8 \%$ and dry rangeland $0.3 \%$. Eleven genera were caught; Anopheles, Mansonia, Coquillettidia, Culex, Ficalbia, Aedomyia, Aedes, Theobaldia, Uranotaenia, Orthopodomyia, and Hodgesia.

Mosquitoes of genus Mansonia (constituting Mansonia africana and $M$. uniformis) dominated flooded lakeshore land habitat with a catch of $98 \%$. The swamp marshy area was the preferred habitat for three genera of mosquitoes that are key in transmission of RVF; Aedes, Culex (constituting Culex pipens pipens, Culex pipens quinquefasciatus and Culex tritaeniorhynchus species) and Coquillettidia with an abundance catch of $96.9 \%, 64.1 \%$ and $53 \%$ respectively. In the dry rangeland area, the catch of Aedes mosquitoes was $1.2 \%$, Culex $0.5 \%$ and Mansonia below 0.1\%. Flooded lakeshore land habitat had the lowest mosquitoes' Simpson's Diversity Index of 0.13, while the swamp marshy and dry rangeland had Simpson's Diversity Index of 0.56 and 0.57 respectively.

\section{Prevalence of RVF infection}

The overall prevalence of the RVF disease in livestock species from the basin during the period of extreme unprecedented flooding of
Lake Baringo was 12\% (N=77). Sheep had the highest risk of infection at 19\% prevalence, followed by Goats with $12 \%$ and Cattle at $9 \%$. Poultry had the lowest prevalence of infection for RVF at $5 \%$.

\section{Prevalence of RVF infection in diverse habitats}

The prevalence and potential risk to infection differed with the type of habitat. The highest risk of livestock to infection with RVF disease was from the swamp marshy habitat at $7.8 \%$, followed by flooded lakeshore land at $2.6 \%$. Livestock from the dry rangeland were not infected (Table 1). The measure of association computed as odds ratio (OR) showed that a statistical association existed between the disease and exposure to mosquitoes of genus Mansonia in flooded shoreline. The odds of infection to livestock resident in the flooded shoreline habitat that was heavily infested with Mansonia (98\%) was 8.0 times higher than in dry rangeland habitat where infestation was below $0.1 \%$.

From the study, goats from the swamp marshy habitat faced the highest risk to the disease with RVF prevalence of $40 \%$, followed by sheep at $25 \%$. In the flooded lakeshore land, sheep was the most affected with RVF prevalence of $33 \%$. In this study, it emerged that the habitat had a significant role at $\mathrm{p}<0.05$ in transmission of RVF disease $\left(F_{(2,9)}=10.5\right.$ $\mathrm{p}=0.004)$. The Tukey HSD test for multiple comparison showed a significance difference in infections between livestock resident in swamp and flooded habitats $(\mathrm{p}<0.036)$; between swamp and dry rangeland $(\mathrm{p}<0.003)$. However, there was no significant differences in infection based simply on the species of livestock $\left(F_{(3,4)}=0.02 p=0.5\right)$. 
Table 1. Risk of livestock to infection with RVFV from the three ecological habitats of Lake Baringo basin, Kenya

\begin{tabular}{|c|c|c|c|c|c|c|c|c|}
\hline \multirow[b]{2}{*}{ Livestock species } & \multicolumn{2}{|c|}{ Swamp marshy habitat } & \multicolumn{2}{|c|}{ Flooded habitat } & \multicolumn{2}{|c|}{$\begin{array}{l}\text { Dry } \\
\text { rangeland } \\
\text { habitat }\end{array}$} & \multirow[b]{2}{*}{$\mathbf{N}$} & \multirow[t]{2}{*}{ Total } \\
\hline & $\mathbf{n}$ & +ve & $\mathbf{n}$ & +ve & $\mathbf{n}$ & +ve & & \\
\hline Goats & $\mathrm{n}=5$ & $2(40 \%)$ & $\mathrm{n}=5$ & $0(0 \%)$ & $\mathrm{n}=7$ & $0(0 \%)$ & $\mathrm{N}=17$ & $2(12 \%)$ \\
\hline Sheep & $\mathrm{n}=8$ & $2(25 \%)$ & $n=3$ & $1(33 \%)$ & $n=5$ & $0(0 \%)$ & $\mathrm{N}=16$ & $3(19 \%)$ \\
\hline poultry & $\mathrm{n}=8$ & $1(13 \%)$ & $\mathrm{n}=8$ & $0(0 \%)$ & $n=6$ & $0(0 \%)$ & $\mathrm{N}=22$ & $1(5 \%)$ \\
\hline Cattle & $\mathrm{n}=8$ & $1(13 \%)$ & $\mathrm{n}=6$ & $1(17 \%)$ & $\mathrm{n}=8$ & $0(0 \%)$ & $\mathrm{N}=22$ & $2(9 \%)$ \\
\hline (+ve/n ) & $\mathrm{n}=\mathbf{2 9}$ & $6(21 \%)$ & $\mathrm{n}=\mathbf{2 2}$ & $2(9 \%)$ & & $0(0 \%$ & & \\
\hline$(+v e / \mathrm{N})$ & & $7.8 \%$ & & $2.6 \%$ & & $0 \%$ & $\mathrm{~N}=77$ & $8(12 \%)$ \\
\hline
\end{tabular}

\section{Discussion}

Studies of an ecosystem in respect to environment, ecology, interaction of the vector with diverse hosts and other demographic variations help in mapping and description of risk factors including understanding spatial epidemiological patterns of an infectious disease (Elliot \& Wartenberg, 2004). In this study, the interaction of the changing environmental factors with multiple species of the mosquitoes that vector RVF and hosts from the habitats facilitated circulation and sustenance of the virus in Lake Baringo basin. Previous studies have associated outbreaks of RVF disease with El nino rains and ensuing floods. The major outbreak of 2006/2007 in the Lake Baringo was attributed to El nino rains that covered the entire basin (Breiman et al., 2010; Nguku et al., 2010).

In our study, the lakeshore habitat was the most affected by the unprecedented extreme floods of 2012-2013. The rising lake waters never reached the swamp marshy and dry rangeland habitats. Normal floods associated to seasonal rains were not experienced during the study period in the basin. The low risk of infection with RVF encountered from the lakeshore land habitat was as a result of interaction of the altered environmental factors within the ecology occasioned by excess lake waters. The lake waters flooding lakeshore land habitat, emergence of floating macrophytes favoured breeding and proliferation of Mansonia africana and $M$. uniformis species of mosquitoes to other genera giving rise to uneven mosquito diversity. Dense P. juliflora protected them from desiccation. Decomposing submerged animal waste and vegetation including other debris modified the biological, environmental and physical factors within the habitat and breeding sites of mosquitoes that are primary vectors of RVF disease.

The swamp marshy habitat supported diverse mosquitos' genera with the high risk of infection with RVFV exacerbated by high catches of genera Aedes and Culex species that included Culex pipens pipens, Culex pipens quinquefasciatus and Culex tritaeniorhynchus species. According to Seufi (2010), these species acts as primary and secondary vectors of RVF. Fresh water from the springs, broad and axial leaved plants, and occasional precipitation including scattered pools of water favoured breeding and survival of diverse species of mosquitoes that vector RVFV.

Studies by Lichoti (2014) in Lake Baringo basin showed that in times of normal rains, livestock resident in the lakeshore land area were at highest risk of infection with RVFV than in other habitats with the risk averaging 26.5\% $24.4 \%$. Similar findings were documented in a study by Munyua (2010) during El nino rainy 
season experienced in 2006/2007 with the RVF prevalence ranging from $36.5 \%-27.8 \%$. Interestingly, the study by Munyua (2010) recorded $0 \%$ infections in livestock from swamp marshy area (Kapkuikui village) whereas our study recorded a $21 \%$ infection of those resident in the habitat. This study shows a new epidemiological pattern of exposure to mosquitos' of genus Mansonia and the RVF disease in flooded shoreline. In this habitat, the odds ratio of 8.0 meant that the circulation and sustenance of the RVFV in livestock can be attributed to heavy habitation by mosquitos' of genus Mansonia. This highlights the importance of spatial epidemiology and stratification of an ecosystem in understanding prevailing risk factors that aid in sustenance and outbreak of RVF.

Poultry resident in swamp marshy and flooded lakeshore land area were shown to be infected with RVF virus. The two habitats harboured the mosquitoes of genus Coquillettidia which according to Molaei (2008) is mostly ornithophilic but can feed on other available domestic animals and humans. The study by Molaei (2008) further clarified that the genus supports enzootic amplification of RVFV and facilitate transmission from nonviremic birds to mammals. In this study, it is therefore high likely that the non-viremic RVFV in poultry could have been one of the sources of circulating virus in the Lake Baringo basin.

\section{Conclusion}

In conclusion, unlike the floods caused by heavy rainfall, the rise of the waters of Lake Baringo basin during the extreme unprecedented flooding in 2010-2014 was limited to expansive lakeshore land habitat. The flooding lake waters caused prolonged disruption of biotic and abiotic factors creating unfavourable breeding sites for most of mosquitos' species and subsequently low prevalence of RVF. Exposure of livestock to mosquitoes of genus Mansonia ensures circulation of RVFV at low levels in a herd which can be a source of an outbreak in case of habitation by other primary vectors under and existence of favourable environmental conditions. Flocking of livestock and wildlife together, exposure to diverse species of mosquitoes and existence of numerous small scale scattered microhabitats optimal for mosquitoes breeding are key primary factors in sustenance of RVF in livestock in swampy marshy habitat. With adequate precipitation, the swamp marshy ecology is a potential source of an outbreak in an endemic RVF ecosystem.

\section{Recommendations}

This study recommends timely vaccination of livestock resident in Lake Baringo basin against the RVF disease and establishment of sentinel livestock herd from the area for continuous surveillance of the disease. There is a need for further study to understand the transmission of non-viremic RVF to domestic poultry and the role they play in sustenance of the RVF virus in livestock

\section{Acknowledgments}

The authors would like to acknowledge the Kenyatta University, International Livestock Research Institute, Director of Veterinary Services and staff from Public Health Laboratory in Marigat for their support in this research. We acknowledge the following individuals, Karegi Frida, Lelenguyah Geoffrey, Michael Rotich, Moses Ogugo and James Wanjama for field sampling, laboratory diagnosis and logistics. The research was funded through financial support and resources from the Kenyatta University (Vice Chancellors Research Fund) and the Directorate of Veterinary services. 


\section{References}

Abudurexiti, A., Adkins, S., Alioto, D., Alkhovskiy, S., Zupanc, T., Ballinger, M., Bente, D., Beer, M., Bergeron, E., Blair, C., Briese, T., Buchmeier, M., Burt, F., Calisher, C., Cháng, C., Charrel, R., Choi, I.-R., Clegg, J., Torre, J., \& Kuhn, J. (2019). Taxonomy of the order Bunyavirales: Update 2019. Archives of Virology, 164. https://doi.org/10.1007/s00705-01904253-6

Anyamba, A., Linthicum, K. J., \& Tucker, C. J. (2001). Climate-disease connections: Rift Valley Fever in Kenya. Cad Saude Publica, 17(133-40).

Breiman, R. F., Murithi, R. M., Munyua, P., Ithondeka, P. M., Macharia, J. M., Hightower, A., Luman, B., \& M.K, N. (2010). Rift Valley Fever in Kenya: History of epizootics and identification of vulnerable districts. Epidemiology Infection, 139, 372-380.

Breiman R.F., Njenga, M. K., Cleaveland, S., Sharif, S., Mbabu, M., \& King, L. (2008). Lessons from the 2006-2007 Rift Valley fever outbreak in East Africa: Implications for prevention of emerging infectious diseases. Future Virology, 3(5), 411-417. https://doi.org/10.2217/17460794.3. 5.411

Chevalier, V., Rocque, S. de la, Baldet, T., Vial, L., \& Roger, F. (2004). Epidemiological processes involved in the emergence of vector-borne diseases: West Nile fever, Rift Valley fever, Japanese encephalitis and Crimean-Congo haemorrhagic fever. Rev. Sci. Tech. Off. Int. Epiz, 23(2), 535-555.

Daubney, R., Hudson, J. R., \& Garnham, P. (1931). Enzootic hepatitis or Rift Valley fever. An undescribed virus disease of sheep, cattle and man from East Africa. The Journal of Pathology and Bacteriology, 34, 545-579.

Elliott, P., \& Wartenberg, D. (2004). Spatial epidemiology: Current approaches and future challenges. Environmental Health Perspectives, 112(9), 998-1006.
PubMed.

https://doi.org/10.1289/ehp.6735

Johansson, J., \& Svensson, J. (2002). Land degradation in the semi-arid catchnment of Lake Baringo, Kenya., A minor field study of physical causes with a socioeconimic aspect Department. Department of Physical Geography GÖTEBORG 2002, Institutionen för geovetenskaper Naturgeografi Geovetarcentrum, Sweden.

Johnson, N., L. Paul Phipps, \& Mansfield, K. (2012). Rapid Molecular Detection Methods for Arboviruses of Livestock of Importance to Northern Europe. Journal of Biomedicine and Biotechnology, 2012. https://doi.org/10.1155/2012/71940 2

Jost, C. C., Nzietchueng, S., Kihu, S., Bett, B., Njogu, G., Swai, E. S., \& Mariner, J. C. (2010). Epidemiological Assessment of the Rift Valley Fever Outbreak in Kenya and Tanzania in 2006 and 2007. American Journal of Tropical Medicine and Hygiene, 83(Suppl2), 65-72.

Lichoti, J. K., Kihara, A., Oriko, A. A., Okutoyi, L. A., Wauna, J. O., Tchouassi, D. P., Tigoi, C. C., Kemp, S., Sang, R., \& Mbabu, R. M. (2014). Detection of Rift Valley Fever Virus Interepidemic Activity in Some Hotspot Areas of Kenya by Sentinel Animal Surveillance, 2009-2012. Veterinary Medicine International, 2014, 379010. https://doi.org/10.1155/2014/37901 0

Molaei, G., Andreadis, T. G., Armstrong, P. M., \& Diuk-Wasser, M. (2008). HostFeeding Patterns of Potential Mosquito Vectors in Connecticut, USA: Molecular Analysis of Bloodmeals from 23 Species of Aedes, Anopheles, Culex, Coquillettidia, Psorophora, and Uranotaenia. Journal Medical Entomology, 45(6), 1143-1151.

Munyua, P., Muriithi RM, Wainwright S, Githinji J, Hightower A, Mutonga D, Macharia J, Ithondeka P, Njenga M. K, Musaa J, Breiman R. F, \& Bloland P. (2010). Rift Valley fever outbreak in livestock in Kenya. American Journal of 
Tropical Medicine and Hygiene, 83(2), 58-64.

Mwangi, E., \& Swallow, B. (2005). Invasion of Prosopis juliflora and local livelihoods:

Case study from the lake Baringo area of Kenya (Working Paper No. 3). World Agroforestry Center (ICRAF).

Nanyingi, M., Munyua, P., Kiama, S., Muchemi, G., Thumbi, S., Bitek, A., Bett, B., Muriithi, R., \& Njenga, M. (2015). A systematic review of Rift Valley Fever epidemiology. Infection Ecology \& Epidemiology, 1931-2014.

Nguku, P. M., Sharif, S. K., Mutonga, D., Jared Omolo, Mohammed, O., Farnon, E. C., Allen Hightower, L. Hannah Gould, Carol Rao, Rosemary Sang, David Schnabel, Daniel R. Feikin, \& M. Kariuki Njenga. (2010). An Investigation of a Major Outbreak of Rift Valley Fever in Kenya: 2006-2007. American Journal of Hygiene, 83(Suppl 2), 5-13.

Obando, J., Onywere, S., Shisanya, C., Ndubi, A., Masiga, D., Irura, Z., Mariita, N., \& Maragia, H. (2016). Impact of ShortTerm Flooding on Livelihoods in the Kenya Rift Valley Lakes (pp. 193-215). https://doi.org/10.1007/978-4-43156000-5_12

Odada, E. O., Onyando, J. O., \& Obudho, P. A. (2006). Lake Baringo: Addressing threatened biodiversity and livelihoods. Lakes $\mathcal{E}$ Reservoirs: Research and Management, 11, 1-12.

OIE Terrestrial Manual. (2016). Rift Valley Fever (Infection with Rift Valley Fever Virus). World Organization For.

Okech, E., Kitaka, N., Omondi, S., \& Verschuren, D. (2019). Water level fluctuations in Lake Baringo, Kenya, during the 19th and 20th centuries: Evidence from lake sediments. African Journal of Aquatic Science, 44(1), 25-33. https://doi.org/10.2989/16085914.20 19.1583087

Onywere, S., Shisanya, C., Obando, J., Masiga, D.K., Irura, Z., Mariita, N.O., Maragia, H., \& Ndubi, A. (2013b). Understanding the Environment, Promoting Health in Lake Baringo and Bogoria Drainage Basin. Environmental Science.

Paula, M. B. de, Duarte, A. R. de C., Gomes, A. de C., Natal, D., \& Mucci, L. F. (2012). Effects of Artificial Flooding for Hydroelectric Development on the Population of Mansonia humeralis (Diptera: Culicidae) in the Paran'a River, S ao Paulo, Brazil. Journal of Tropical Medicine, 2012(ID 598789), 6 pages. https://doi.org/10.1155/2012/59878 9

Restrepo, A. M. C., Yu Rong Yang, Donald P. McManus, Darren J. Gray, Patrick Giraudoux, Tamsin S. Barnes, Gail M. Williams, Ricardo J. Soares Magalhães, Nicholas A. S. Hamm, \& Archie C. A. Clements. (2016). The landscape epidemiology of echinococcoses. Infectious Diseases of Poverty, 5. https://doi.org/DOI 10.1186/s40249-016-0109-x

Rich, K. M., \& Wanyoike, F. (2010). An Assessment of the Regional and National Socio-Economic Impacts of the 2007 Rift Valley Fever Outbreak in Kenya. American Journal of Tropical Medicine and Hygiene, 83(Suppl2), 5557.

Sang, R., Kioko, E., Lutomiah, J., Warigia, M., Ochieng, C., O'Guinn, M., John S, Koka, L. H., Godsey, M., Hoel, D., Hanafi, H., Miller, B., Schnabel, D., Breiman, R. F., \& Richardson, J. (2010). Rift Valley Fever Virus Epidemic in Kenya, 2006/2007: The Entomologic Investigations. American Journal of Tropical and Medical Hygiene, 83(suppl 2), 28-37.

Seufi, A. M., \& Galal, F. H. (2010). Role of Culex and Anopheles mosquito species as potential vectors of rift valley fever virus in Sudan outbreak, 2007. BMC Infectious Diseases, 10(1), 65. https://doi.org/10.1186/1471-233410-65

Terer, T., Muasya, A. M., Farid, D.-G., Ndiritu, G. G., \& Triest, L. (2012). Integrating local ecological knowledge and management practices of an isolated semi-arid papyrus swamp (Loboi, 
Kenya) into a wider conservation framework. Journal of Environmental Management, 93, 7184.

Tigoi, C., Lwande, O., Orindi, B., Irura, Z., Ongus, J., \& Sang, R. (2015). Seroepidemiology of Selected Arboviruses in Febrile Patients Visiting Selected Health Facilities in the Lake/River Basin Areas of Lake Baringo, Lake Naivasha, and Tana River, Kenya. Vector-Borne and Zoonotic Diseases, 15(2).

Wangara, F., Kipruto, H., Ngesa, O., Kayima, J., Masini, E., Sitienei, J., \& Ngari, F. (2019). The spatial epidemiology of leprosy in Kenya: A retrospective study. PLOS Neglected Tropical Diseases, 13(4), e0007329. https://doi.org/10.1371/journal.pnt d. 0007329

Wetang'ula, G. N., Kubo B.M, \& Were J.O. (2012). Environmental Baseline Study For Geothermal Developments: Case Study Arus-Bogoria Geothermal Prospects, Kenya (Oct. 29-Nov. 19, 2010). UNU-GTP, GDC and KenGen.

Young, A. T. (2021). Al Young Studios Biodiversity Calculator. Retrieved March 4, 2021, from https://www.alyoung.com/labs/bio diversity_calculator.html 